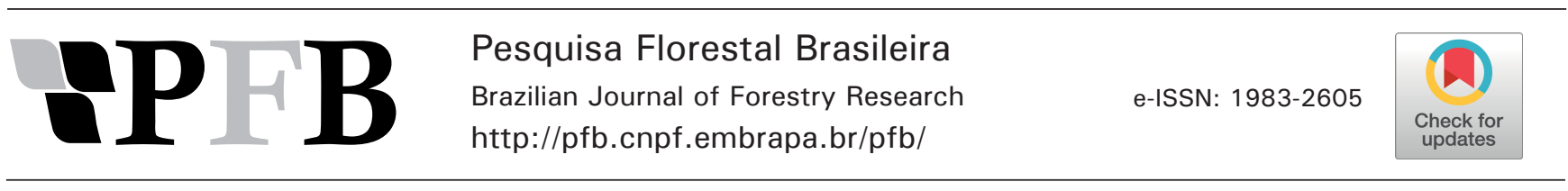

\title{
Influência da temperatura final de carbonização nas características do carvão vegetal de espécies tropicais
}

\author{
Renata Carvalho da Silva1(D), Raquel Marchesan ${ }^{1}$ (D), Matheus Rodrigues Fonseca²(D), Ana Carolina Caixeta Dias ${ }^{3}$ (D), \\ Lívia Cássia Viana' ${ }^{10}$
}

${ }^{1}$ Universidade Federal do Tocantins, Rua Badejós, Lote 7, Chácaras 69/72, Zona Rural, CP. 66, CEP 77402- 970, Gurupi, TO, Brasil

${ }^{2}$ Senai, Rua Dr. José Amílcar Congro Bastos, 1313, Vila Nova, CEP 79604-250, Três Lagoas, MS, Brasil

"Autor correspondente:
raquelmarchesan@uft.edu.br

Termos para indexação:

Pirólise

Aquecimento

Composição química imediata

Index terms:

Pyrolysis

Heating

Immediate chemical composition

Histórico do artigo:

Received in 12/02/2018

Accepted in 13/09/2018

Published in 29/12//2018

doi: 10.4336/2018.pfb.38e201801573
Resumo - Este estudo teve por objetivo a caracterização energética do carvão de resíduos de cinco espécies provenientes de marcenarias no município de Gurupi, TO, bem como avaliar a influência do tempo e temperatura final de carbonização. Dos resíduos de cada uma das cinco espécies, foram obtidos vinte corpos de prova. O carvão vegetal foi obtido por meio da pirólise da madeira em forno tipo mufla, onde foram utilizadas duas marchas com temperaturas finais de carbonização de $450{ }^{\circ} \mathrm{C}$ e $500{ }^{\circ} \mathrm{C}$ e tempo de carbonização de 6 h e 7 h, respectivamente. Para a determinação da densidade aparente e do rendimento gravimétrico, os carvões foram pesados em balança analítica e medidos com paquímetro. A análise química imediata (AQI) foi realizada em forno mufla, para a determinação dos materiais voláteis, carbono fixo e cinzas, sendo também calculado o poder calorífico. O rendimento gravimétrico apresentou valores médios aceitáveis para todas as espécies e temperaturas (36,4\%). Os teores de materiais voláteis $(27,7 \%)$, carbono fixo $(70,6 \%)$ e cinzas $(1,7 \%)$ também foram considerados aceitáveis. O poder calorífico apresentou valores dentro dos padrões recomendados, apresentando alto potencial energético. A temperatura final de carbonização recomendada foi de $500^{\circ} \mathrm{C}$.

\section{Influence of the final carbonization temperature on the characteristics of tropical species charcoal}

\begin{abstract}
The aim of this study was to determine the energetic characteristics of the charcoal of five species from wood residues in the municipality of Gurupi, Tocantins State, Brazil, as well as evaluating the influence of final carbonization time and temperature. Twenty test samples were obtained from each of the five species. The charcoal was obtained by wood pyrolysis in a muffle furnace, where two heating speeds with final carbonization temperatures of $450^{\circ} \mathrm{C}$ and $500^{\circ} \mathrm{C}$ for $6 \mathrm{~h}$ and $7 \mathrm{~h}$, respectively, were used. To determine the apparent density and the gravimetric yield, the charcoal was weighed on an analytical scale and measured with a caliper. The immediate chemical analysis (ICA) was carried out. It was used a muffle furnace to determine volatile materials, fixed carbon and ash and the calorific value was calculated. The gravimetric yield presented acceptable average values for all species and temperatures (36.4\%). Acceptable values were found for volatile materials (27.7\%), fixed carbon (70.6\%) and ashes $(1.7 \%)$. Calorific values were within the recommended standards, presenting high energetic potential. The recommended final temperature of carbonization is $500{ }^{\circ} \mathrm{C}$.
\end{abstract}




\section{Introdução}

A madeira ainda é o produto de maior comercialização da floresta e dentre os produtos provenientes da madeira, o carvão vegetal possui uma posição de destaque na geração de energia. Dados da Food and Agriculture Organization of the United Nations (FAO) (2017) apontam a madeira como a mais importante fonte de energia renovável, respondendo por cerca de $6 \%$ da oferta global de energia primária. A madeira utilizada para a produção de carvão tem duas origens básicas: florestas plantadas, que no Brasil, em sua grande maioria, são espécies do gênero Eucalyptus, e florestas nativas (Carvalho et al., 2017).

O Brasil é maior produtor mundial de carvão vegetal, sendo os principais consumidores os setores de ferrogusa, aço e ferro-liga e, em menor escala, o comércio e o consumidores residenciais (Leite et al., 2015). A grande demanda do carvão vegetal para suprir as necessidades da indústria é um dos fatores que contribui para o desmatamento, pois não há florestas plantadas para suprir toda a demanda, acarretando na exploração desordenada das matas nativas (Costa et al., 2014).

As indústrias madeireiras geram grande quantidade de resíduos, resultado do baixo rendimento, que dispersos ao meio ambiente podem trazer sérios problemas de poluição, especialmente, em sua incineração sem um prévio controle ambiental. Estudos mostram que o desperdício da madeira processada nas indústrias de beneficiamento é de aproximadamente $50 \%$, o qual vai depender da espécie processada (Biasi \& Rocha, 2007), da qualidade das toras e dos equipamentos utilizados. Há, portanto, a necessidade de se buscar conhecimentos sobre o comportamento da madeira de espécies nativas na carbonização, permitindo caracterizar as propriedades do carvão vegetal, oriundo de resíduos de exploração florestal e resíduo de indústrias madeireiras, considerando o grande desperdício dos mesmos. Do ponto de vista econômico, o uso de carvão vegetal possui vantagens na siderurgia se comparado ao coque, por apresentar baixo teor de cinzas, baixo teor de enxofre e fósforo e por ser mais reativo. No que diz respeito ao meio ambiente o aproveitamento dos resíduos da madeira apresenta fundamental importância, pois se trata de um produto renovável, além de evitar que seja queimado a céu aberto (Oliveira et al., 2010).

O carvão vegetal deve ter suas propriedades estabelecidas de acordo com a origem e qualidade da matéria prima e a influência da temperatura final de carbonização. A temperatura e a velocidade de aquecimento na pirólise podem influenciar a qualidade e o rendimento do carvão vegetal. Oliveira et al. (2010) estudaram a influência do tempo e das temperaturas finais na carbonização de Eucalyptus pellita F. Muell. nas propriedades físicas e químicas do carvão vegetal. Os autores observaram que a taxa de aquecimento de $1,25{ }^{\circ} \mathrm{C} \mathrm{min}^{-1}$ com temperatura final de $450{ }^{\circ} \mathrm{C}$ e tempo total de carbonização de $6 \mathrm{~h}$ apresentou o maior rendimento gravimétrico, elevado teor de carbono fixo e de poder calorífico do carvão. Trugilho \& Silva (2001), em trabalho realizado com carbonização de jatobá a diferentes temperaturas (variando de $300^{\circ} \mathrm{C}$ até $900^{\circ} \mathrm{C}$ ), afirmaram que a temperatura final de carbonização foi determinante na qualidade do carvão, em que houve diminuição do rendimento gravimétrico, aumento do teor de carbono fixo e cinzas e diminuição do teor de materiais voláteis com o aumento da temperatura.

O conhecimento da qualidade da madeira é importante, quando o objetivo final é a produção de carvão vegetal de elevada qualidade e alto rendimento. Propriedades como o poder calorífico, densidade básica, composição química e umidade da madeira são os principais fatores para a classificação da madeira para esse uso (Oliveira et al., 2010). Segundo Santos et al. (2011), espécies com maiores valores de densidade básica apresentam maior poder calorífico e, desta forma, maior rendimento energético. Madeiras de densidades mais elevadas produzem carvão com maior densidade aparente. Quanto maior a densidade aparente do carvão vegetal, melhor será o aproveitamento do volume útil do alto-forno siderúrgico, permitindo aumento da sua produtividade em um determinado espaço de tempo (Froehlich \& Moura, 2017).

Dentre as variáveis que podem predizer a qualidade do carvão vegetal, destaca-se a densidade relativa aparente, umidade, composição química imediata (materiais voláteis, carbono fixo e cinzas) e o poder calorífico superior (Oliveira et al., 2010).

Segundo Oliveira et al. (2010) as propriedades químicas consideradas satisfatórias para o carvão são os maiores teores de carbono fixo, menores teores de substâncias voláteis e cinzas, e estão associadas à madeira com altos teores de lignina, para determinadas condições de carbonização, sendo que a temperatura final tem grande influência na qualidade do carvão vegetal.

Em relação ao potencial energético, o mesmo é influenciado diretamente pelo teor de carbono fixo e materiais voláteis. Trugilho \& Silva (2001) observaram 
aumento do poder calorífico com o aumento da temperatura final de carbonização. Segundo os autores, isto ocorreu devido ao teor de carbono fixo também ter aumentado com o aumento da temperatura.

Reconhecendo a importância e a potencialidade do carvão vegetal, este estudo teve como objetivo a caracterização energética do carvão de cinco espécies provenientes de resíduos de marcenarias no município de Gurupi, TO, bem como avaliar a influência do tempo e temperatura final de carbonização.

\section{Material e métodos}

\section{Localização e características da região de coleta da madeira}

Foram utilizados resíduos de madeira obtidos em uma marcenaria no município de Gurupi, TO. A madeira utilizada na marcenaria é proveniente do município de Paragominas, distante $320 \mathrm{~km}$ de Belém, PA. Foram selecionados resíduos de cinco espécies tropicais: Cordia geoldiana Huber (freijó), Hymenolobium petraeum Ducke (angelim-pedra), Hymenaea courbaril (jatobá), Tabebuia spp. (ipê) e Astronium lecointei Ducke (muiracatiara), tomando-se como base a maior disponibilidade por serem as espécies mais utilizadas na marcenaria.

\section{Amostragem}

Foram obtidos vinte corpos de prova de cada espécie, sendo dois tratamentos por espécie com dez repetições cada.
Os corpos de prova foram confeccionados com dimensões aproximadas de 2,0 cm x 2,0 cm x 5,0 cm (largura $\mathrm{x}$ espessura $\mathrm{x}$ comprimento), e demarcados com a letra inicial de cada espécie, o número de cada repetição e o número do tratamento. Os corpos de provas foram os mesmos para todos os testes realizados neste estudo.

\section{Densidade básica da madeira}

A densidade básica da madeira foi determinada pelo método da balança hidrostática, baseado na norma ASTM D-2395 da American Society for Testing and Materials (ASTM) (2005). Os corpos de prova foram deixados em água até a saturação total, para a determinação do volume úmido. Posteriormente, os mesmos foram levados à estufa para secagem a $0 \%$ de umidade a uma temperatura de $103{ }^{\circ} \mathrm{C} \pm 2{ }^{\circ} \mathrm{C}$, até atingirem massa constante.

\section{Pirólise da madeira}

Para produção do carvão vegetal, foram utilizados 20 corpos de prova, sendo dois tratamentos com 10 repetições para cada espécie, com dimensões de aproximadamente 2,0 cm x 2,0 cm x 5,0 cm (largura x espessura $\mathrm{x}$ comprimento).

Os corpos de prova foram colocados em estufa para secagem a $0 \%$ de umidade, a uma temperatura de $103{ }^{\circ} \mathrm{C} \pm 2{ }^{\circ} \mathrm{C}$, até atingirem massa constante. Estas amostras foram carbonizadas em forno tipo mufla com controle da temperatura final programada e adaptado para recuperar o licor pirolenhoso. O controle de temperatura foi realizado em duas marchas de carbonização (tratamentos) distintas (Tabela 1).

Tabela 1. Temperatura e tempo de carbonização em função da marcha de carbonização.

Table 1. Temperature and time of carbonization due to carbonization heating speed.

\begin{tabular}{|c|c|c|c|c|c|c|c|c|}
\hline \multirow{2}{*}{ Marcha } & \multicolumn{6}{|c|}{ Temperatura ${ }^{\circ} \mathbf{C}$} & \multirow{2}{*}{$\begin{array}{l}\text { Taxa de aquecimento } \\
\qquad\left({ }^{\circ} \mathrm{C} \text { min }^{-1}\right)\end{array}$} & \multirow{2}{*}{ Tempo tota } \\
\hline & 150 & 200 & 250 & 350 & 450 & 500 & & \\
\hline 1 & $1 \mathrm{~h}$ & $1 \mathrm{~h}$ & $1 \mathrm{~h} 30 \mathrm{~min}$ & $1 \mathrm{~h} 30 \mathrm{~min}$ & $1 \mathrm{~h}$ & - & 1,25 & $6 \mathrm{~h}$ \\
\hline 2 & $1 \mathrm{~h}$ & $1 \mathrm{~h}$ & $1 \mathrm{~h} 30 \mathrm{~min}$ & $1 \mathrm{~h} 30 \mathrm{~min}$ & 1 ha & $1 \mathrm{~h}$ & 1,19 & $7 \mathrm{~h}$ \\
\hline
\end{tabular}

\section{Rendimento gravimétrico do carvão vegetal}

$\mathrm{O}$ rendimento gravimétrico foi calculado a partir da relação entre as massas secas do carvão e da madeira, que foram obtidas por pesagem de cada corpo de prova em balança analítica.

\section{Densidade aparente do carvão}

A densidade aparente do carvão foi determinada de acordo com a norma NBR 9156 da Associação Brasileira de Normas Técnicas (ABNT) (1985). O volume foi calculado por meio das dimensões de comprimento, 
largura e espessura de cada corpo de prova. As dimensões foram obtidas com paquímetro e a massa pela pesagem em balança analítica. O cálculo da densidade aparente foi realizado por meio da relação entre o volume do carvão e o peso seco do mesmo.

\section{Determinação do indice de quebra do carvão vegetal}

$O$ índice de quebra do carvão foi determinado de acordo com a norma da ABNT NBR 7416 (Associação Brasileira de Normas Técnicas, 1984) onde foram realizadas três quedas livres de $1,83 \mathrm{~m}$ de altura para cada corpo de prova do carvão. Após a terceira queda, o maior fragmento restante foi pesado. O índice de quebra foi calculado a partir da Equação 1.

$$
\mathrm{IQ}=\left(1-\frac{\mathrm{Pf}}{\mathrm{PF}}\right) * 100
$$

Em que: $\mathrm{IQ}=$ índice de quebra (\%); $\mathrm{Pf}=$ peso do fragmento após o ensaio (g); $\mathrm{PF}=$ peso carvão antes do ensaio $(\mathrm{g})$.

\section{Análise química imediata (AQI)}

O carvão vegetal das dez repetições de cada tratamento foi triturado, peneirado em peneiras com malha de 40 e 60 mesh e disposto em cadinhos, pesado e encaminhado para secar em estufa a $103{ }^{\circ} \mathrm{C} \pm 2{ }^{\circ} \mathrm{C}$, por $30 \mathrm{~min}$. A análise química imediata foi realizada baseando-se nas normas ASTM D 1762-84 (American Society for Testing and Materials, 2007) e ABNT NBR 8112/83 (Associação Brasileira de Normas Técnicas, 1983) onde se determinaram os percentuais de materiais voláteis, teor de carbono fixo e cinzas do carvão.

\section{Determinação do poder calorífico do carvão vegetal}

O poder calorífico do carvão foi estimado seguindo a metodologia de Vale et al. (2002), aplicando-se a Equação 2.

$$
\mathrm{PCS}=4934,43+33,27 * \mathrm{CF}
$$

Em que: $\mathrm{PCS}=$ poder calorifico do carvão $\left(\mathrm{Kcal} \mathrm{kg}^{-1}\right) ; \mathrm{CF}$ $=$ teor de carbono fixo $(\%)$.

\section{Análises estatísticas}

O delineamento experimental utilizado foi o inteiramente casualizado, com arranjo em fatorial 5 x 2, considerando dois fatores: cinco espécies e duas marchas de carbonização. Primeiramente foi testada a homogeneidade das variâncias pela ANOVA para verificar a existência ou não de diferenças entre os fatores e em seguida foi realizado o teste de normalidade de Shapiro-Wilk. A estatística paramétrica foi aplicada nos parâmetros de rendimento gravimétrico e do poder calorífico do carvão vegetal, pela comparação das médias pelo teste de Tukey ao nível de probabilidade de 1\%.

Para os demais parâmetros utilizou-se a estatística não paramétrica, que é indicada quando a amostragem é realizada para um número menor de repetições ou quando não há normalidade entre os dados. Neste caso, a comparação de médias foi feita pelo método de Kruskal-Wallis. Por último, foi realizada a análise de correlação linear de Person, para os parâmetros de densidade básica da madeira, densidade aparente do carvão, índice de quebra do carvão, carbono fixo e poder calorífico superior. O programa estatístico utilizado para as análises foi o Assistat 7.7 pt 2.

\section{Resultados}

\section{Densidade básica}

Na Tabela 2, são apresentados os valores médios de densidade básica dos resíduos de madeira obtidos a partir das espécies avaliadas. A densidade básica, de modo geral, apresentou diferenças significativas entre as cinco espécies estudadas. Dentre as espécies avaliadas, as que apresentaram maior densidade básica foram o ipê, jatobá e a muiracatiara e as que obtiveram menor valor foram o angelim-pedra e o freijó.

Tabela 2. Valores médios de densidade básica de resíduos de madeira de cinco espécies em Gurupi, TO.

Table 2. Average values of basic density of wood residues of five species from Guripi, Tocantins State, Brazil.

\begin{tabular}{ccc}
\hline Espécies & $\begin{array}{c}\text { Densidade básica da madeira } \\
\left(\mathbf{g ~ c m}^{-3}\right)\end{array}$ & CV (\%) \\
\hline freijó & $0,52 \mathrm{~A}$ & 1,7 \\
angelim-pedra & $0,59 \mathrm{~A}$ & 2,4 \\
jatobá & $0,73 \mathrm{~B}$ & 3,6 \\
ipê & $0,97 \mathrm{C}$ & 1,7 \\
muiracatiara & $0,71 \mathrm{~B}$ & 2,8 \\
\hline
\end{tabular}

Médias seguidas pela mesma letra maiúscula na coluna não diferem estatisticamente pelo teste de Kruskal Wallis $(p \geq 0,05)$. CV $=$ coeficiente de variação. 


\section{Rendimento gravimétrico do carvão vegetal}

$\mathrm{Na}$ Tabela 3 constam os valores médios para o rendimento gravimétrico do carvão vegetal para os resíduos das espécies avaliadas e para as respectivas marchas de carbonização de temperatura final de 450 e $500{ }^{\circ} \mathrm{C}$.

Não houve diferenças significativas ao nível de 5\% de probabilidade para a interação das espécies com as marchas de carbonização para o rendimento gravimétrico do carvão vegetal.

A maior média obtida na temperatura final de carbonização de $450{ }^{\circ} \mathrm{C}$ dentre as cinco espécies foi para a muiracatiara, com o valor médio de 39,09\%. $\mathrm{O}$ menor valor médio encontrado foi para o freijó $(35,5 \%)$. Na temperatura final de carbonização de $500^{\circ} \mathrm{C}$ o maior valor médio encontrado foi para a espécie muiracatiara $(37,8 \%)$ e o menor para o angelim-pedra $(33,8 \%)$ (Tabela 3).

Tabela 3. Valores médios de interação do rendimento gravimétrico do carvão de resíduos de madeira de cinco espécies em Gurupi, TO.

Table 3. Average values of gravimetric coal yield interaction from wood residues of five species from Guripi, Tocantins State, Brazil.

\begin{tabular}{cccccc}
\hline \multirow{2}{*}{ Parâmetro } & Espécies & \multicolumn{4}{c}{ Marchas de carbonização } \\
& & $\mathbf{4 5 0}^{\circ} \mathbf{C}$ & $\mathbf{C V}(\mathbf{\%})$ & $\mathbf{5 0 0}{ }^{\circ} \mathbf{C}$ & $\begin{array}{c}\mathbf{C V} \\
\mathbf{( \% )}\end{array}$ \\
\hline & freijó & 35,5 & 1,0 & 33,9 & 2,1 \\
\multirow{2}{*}{$\begin{array}{c}\text { Rendimento } \\
\text { gravimétrico } \\
(\%)\end{array}$} & angelim-pedra & 36,1 & 1,2 & 33,8 & 0,7 \\
& jatobá & 38,4 & 1,4 & 35,0 & 0,9 \\
& ipê & 38,0 & 4,2 & 36,4 & 2,6 \\
\hline
\end{tabular}

$\mathrm{CV}=$ coeficiente de variação.

\section{Qualidade do carvão vegetal}

Os valores médios para densidade aparente do carvão $\left(\mathrm{g} \mathrm{cm}^{-3}\right)$ e do índice de quebra (\%) do carvão vegetal para as cinco espécies avaliadas e para as marchas de carbonização com temperatura final de $450{ }^{\circ} \mathrm{C}$ e de $500^{\circ} \mathrm{C}$ estão apresentados na Tabela 4.

Pode-se observar que para densidade aparente do carvão houve diferenças significativas entre as espécies, entre as marchas de carbonização e interação entre estes dois fatores (Tabela 4). A maior média obtida dentre as cinco espécies estudadas na marcha de carbonização de $450{ }^{\circ} \mathrm{C}$ foi para ipê, com valor médio de $0,70 \mathrm{~g} \mathrm{~cm}^{-3}$, e a menor foi de $0,32 \mathrm{~g} \mathrm{~cm}^{-3}$ para o freijó. Na marcha de carbonização de $500{ }^{\circ} \mathrm{C}$ a maior média obtida foi de $0,74 \mathrm{~g} \mathrm{~cm}^{-3}$, para o ipê, e a menor foi de $0,31 \mathrm{~g} \mathrm{~cm}^{-3}$ para o freijó.

A densidade básica da madeira apresentou uma correlação positiva com o índice de quebra do carvão vegetal $(r=0,692761)$.

Tabela 4. Valores médios da interação de densidade aparente do carvão e índice de quebra do carvão de resíduos de madeira de cinco espécies em Gurupi, TO.

Table 4. Average values of the apparent density of charcoal and charcoal breaking index of wood residues of five species from Guripi, Tocantins State, Brazil.

\begin{tabular}{cccccc}
\hline \multirow{2}{*}{ Parâmetros } & Espécies & \multicolumn{4}{c}{ Marchas de carbonização } \\
\cline { 3 - 6 } & & $\mathbf{4 5 0}{ }^{\circ} \mathbf{C}$ & $\begin{array}{c}\mathbf{C V} \\
\mathbf{( \% )}\end{array}$ & $\mathbf{5 0 0}{ }^{\circ} \mathbf{C}$ & $\begin{array}{c}\mathbf{C V} \\
\mathbf{( \% )}\end{array}$ \\
\hline \multirow{2}{*}{$\begin{array}{c}\text { Densidade } \\
\text { aparente }\left(\mathrm{g} \mathrm{cm}^{-3}\right)\end{array}$} & angelim-pedra & $0,32 \mathrm{~A}$ & 4,8 & $0,31 \mathrm{~A}$ & 5,5 \\
& jatobá & $0,45 \mathrm{AC}$ & 7,1 & $0,45 \mathrm{BC}$ & 7,5 \\
& ipê & $0,70 \mathrm{C}$ & 7,1 & $0,74 \mathrm{C}$ & 5,6 \\
& muiracatiara & $0,41 \mathrm{AB}$ & 16,6 & $0,39 \mathrm{AB}$ & 5,4 \\
\hline \multirow{2}{*}{$\begin{array}{c}\text { Índice de quebra } \\
(\%)\end{array}$} & freijó & $0,29 \mathrm{~A}$ & 91,7 & $0,68 \mathrm{AB}$ & 112,3 \\
& jatobá & $39,82 \mathrm{BC}$ & 20,4 & $47,81 \mathrm{BC}$ & 52,9 \\
& ipê & $46,22 \mathrm{C}$ & 24,3 & $58,66 \mathrm{BC}$ & 35,1 \\
& muiracatiara & $0,22 \mathrm{~A}$ & 137,6 & $0,83 \mathrm{~A}$ & 167,4 \\
\hline
\end{tabular}

Para cada parâmetro, as médias seguidas pela mesma letra maiúscula na coluna não diferem estatisticamente pelo teste de Kruskal Wallis $(\mathrm{p} \geq 0,05)$. $\mathrm{CV}=$ coeficiente de variação.

Na Tabela 5, são apresentados os valores médios referentes ao poder calorífico $\left(\mathrm{Kcal} \mathrm{kg}^{-1}\right)$, para as cinco espécies em estudo e para as marchas de carbonização de $450{ }^{\circ} \mathrm{C}$ e $500{ }^{\circ} \mathrm{C}$. Pode-se observar que, entre as espécies, a que apresentou maior média de poder calorífico do carvão vegetal foi o ipê $\left(7.468,55 \mathrm{Kcal} \mathrm{kg}^{-1}\right)$ e a menor foi do jatobá $\left(7.128,12 \mathrm{Kcal} \mathrm{kg}^{-1}\right)$, na marcha de carbonização de $450^{\circ} \mathrm{C}$. Na marcha de carbonização de $500{ }^{\circ} \mathrm{C}$, o maior valor médio também foi para o ipê $\left(7.502,40 \mathrm{Kcal} \mathrm{kg}^{-1}\right)$, e o menor foi para a muiracatiara $\left(7.062,43 \mathrm{Kcal} \mathrm{kg}^{-1}\right)$. 
Tabela 5. Valores médios de interação de poder calorífico de carvão de resíduos de madeira de cinco espécies em Gurupi, TO.

Table 5. Average values of heat power interaction of coal from wood residues of five species from Guripi, Tocantins State, Brazil.

\begin{tabular}{cccccc}
\hline & & \multicolumn{4}{c}{ Marchas de carbonização } \\
\cline { 3 - 6 } Parâmetro & Espécies & $\mathbf{4 5 0}{ }^{\circ} \mathbf{C}$ & $\begin{array}{c}\mathbf{C V} \\
\mathbf{( \% )}\end{array}$ & $\mathbf{5 0 0}^{\circ} \mathbf{C}$ & $\begin{array}{c}\text { CV } \\
\text { (\%) }\end{array}$ \\
\cline { 3 - 6 } & freijó & $7.244,38 \mathrm{bB}$ & 1,2 & $7.398,48 \mathrm{aA}$ & 1,3 \\
& angelim-pedra & $7.164,97 \mathrm{bB}$ & 1,2 & $7.385,40 \mathrm{aA}$ & 0,7 \\
$\begin{array}{c}\text { Poder } \\
\text { calorífico }\end{array}$ & jatobá & $7.128,12 \mathrm{~B}$ & 0,8 & $7.447,73 \mathrm{aA}$ & 1,6 \\
$\left(\right.$ Kcal kg $\left.^{-1}\right)$ & ipê & $7.468,55 \mathrm{aA}$ & 0,8 & $7.502,40 \mathrm{aA}$ & 1,2 \\
& muiracatiara & $7.178,96 \mathrm{bA}$ & 1,3 & $7.062,43 \mathrm{bB}$ & 2,3 \\
\hline
\end{tabular}

Médias seguidas pela mesma letra minúscula na linha e maiúscula na coluna não diferem estatisticamente pelo teste de Tukey $(\mathrm{p} \leq 0,01) \cdot \mathrm{CV}=$ coeficiente de variação.

\section{Análise química imediata}

As médias para materiais voláteis, carbono fixo e teor de cinzas para as cinco espécies avaliadas e para a temperatura final de carbonização de 450 e $500^{\circ} \mathrm{C}$ são apresentadas na Tabela 6.

Foram observadas diferenças estatísticas significativas entre as espécies em relação ao teor de materiais voláteis, entre as marchas de carbonização e na interação entre os dois fatores ao nível de $1 \%$ de probabilidade. O maior valor médio obtido entre as espécies foi para o jatobá $(32,0 \%)$ e o menor para o ipê $(22,9 \%)$ na marcha de carbonização de $450{ }^{\circ} \mathrm{C}$. Na marcha de carbonização de $500{ }^{\circ} \mathrm{C}$, o maior valor médio obtido foi para muiracatiara $(38,3 \%)$ e o menor também para o ipê $(22,5 \%)$.

Em relação ao teor de carbono fixo, foram observadas diferenças significativas entre as espécies, as marchas de carbonização e interação entre os dois fatores. O maior valor médio obtido entre as cinco espécies foi para ipê $(75,7 \%$ e $76,3 \%)$ e o menor para muiracatiara $(66,4 \%$ e $60,4 \%)$, nas marchas de carbonização de 450 e $500{ }^{\circ} \mathrm{C}$, respectivamente.

Foram observadas diferenças significativas entre as espécies para o teor de cinzas em relação às marchas de carbonização e interação entre os dois fatores. A maior média obtida entre as espécies foi para o jatobá $(2,1 \%)$ e a menor foi para freijó $(1,1 \%)$ para marcha de carbonização de $450{ }^{\circ} \mathrm{C}$. Na marcha de carbonização de $500{ }^{\circ} \mathrm{C}$ a maior média também foi para o jatobá (de $3,0 \%)$ e a menor para o ipê $(1,4 \%)$.
Tabela 6. Valores médios de interação de material volátil, carbono fixo e teor de cinzas de carvão de resíduos de madeira de cinco espécies em Gurupi, TO.

Table 6. Average values of volatile material interaction, fixed carbon and ash content of coal from wood residues of five species from Guripi, Tocantins State, Brazil.

\begin{tabular}{|c|c|c|c|c|c|}
\hline \multirow{2}{*}{ Parâmetros } & \multirow{2}{*}{ Espécies } & \multicolumn{4}{|c|}{ Marchas de carbonização } \\
\hline & & $450{ }^{\circ} \mathrm{C}$ & $\begin{array}{l}\text { CV } \\
(\%)\end{array}$ & $500^{\circ} \mathrm{C}$ & $\begin{array}{l}\text { CV } \\
(\%)\end{array}$ \\
\hline \multirow{5}{*}{$\begin{array}{c}\text { Material } \\
\text { volátil (\%) }\end{array}$} & freijó & 29,4 BCDE & 8,5 & $22,9 \mathrm{ABC}$ & 2,6 \\
\hline & angelim-pedra & 30,4 CDE & 4,9 & 24,5 ABCD & 5,7 \\
\hline & jatobá & $32,00 \mathrm{DE}$ & 6,2 & $22,5 \mathrm{~A}$ & 5,2 \\
\hline & ipê & $22,9 \mathrm{AB}$ & 6,1 & $22,5 \mathrm{AB}$ & 5,5 \\
\hline & muiracatiara & $31,9 \mathrm{DE}$ & 2,5 & $38,3 \mathrm{E}$ & 4,6 \\
\hline \multirow{5}{*}{$\begin{array}{l}\text { Carbono } \\
\text { fixo (\%) }\end{array}$} & freijó & 69,5 ABCD & 3,6 & $75,8 \mathrm{DE}$ & 0,9 \\
\hline & angelim-pedra & $67,8 \mathrm{ABC}$ & 2,1 & 73,7 BCDE & 2,2 \\
\hline & jatobá & $65,9 \mathrm{AB}$ & 2,7 & $74,4 \mathrm{CDE}$ & 1,5 \\
\hline & ipê & $75,7 \mathrm{DE}$ & 1,7 & $76,3 \mathrm{E}$ & 2,1 \\
\hline & muiracatiara & $66,4 \mathrm{ABC}$ & 2,3 & $60,4 \mathrm{~A}$ & 2,9 \\
\hline \multirow{5}{*}{$\begin{array}{c}\text { Teor de } \\
\text { cinzas }(\%)\end{array}$} & freijó & $1,1 \mathrm{~A}$ & 29,2 & $1,4 \mathrm{ABC}$ & 24,8 \\
\hline & angelim-pedra & $1,8 \mathrm{ABCD}$ & 17,7 & 1,9 BCD & 20,0 \\
\hline & jatobá & $2,1 \mathrm{CD}$ & 21,0 & $3,0 \mathrm{D}$ & 90,0 \\
\hline & ipê & $1,2 \mathrm{ABC}$ & 11,8 & $1,4 \mathrm{AB}$ & 31,6 \\
\hline & muiracatiara & $1,3 \mathrm{ABC}$ & 26,9 & $1,4 \mathrm{ABC}$ & 27,7 \\
\hline
\end{tabular}

Para cada parâmetro, as médias seguidas pela mesma letra maiúscula na coluna não diferem estatisticamente pelo teste de Kruskal Wallis ( $\mathrm{p} \geq 0,05)$. $\mathrm{CV}=$ coeficiente de variação.

\section{Discussão}

Os valores médios de densidade básica para as espécies em estudo (Tabela 2) foram próximos aos descritos na literatura para árvores das mesmas espécies. Rodrigues et al. (2011) observaram valores médios de densidade básica para a madeira de ipê, jatobá, muiracatiara e de angelim pedra igual a $0,87 \mathrm{~g} \mathrm{~cm}^{-3}, 0,76 \mathrm{~g} \mathrm{~cm}^{-3}, 0,79 \mathrm{~g} \mathrm{~cm}^{-3}$ e $0,60 \mathrm{~g} \mathrm{~cm}^{-3}$, respectivamente. Lima et al. (2013) observaram valor médio de $0,50 \mathrm{~g} \mathrm{~cm}^{-3}$ para densidade básica de freijó.

Conforme Vale et al. (2010), a densidade básica da madeira está diretamente ligada à densidade aparente do carvão, ou seja, quanto maior for a densidade da madeira, mais denso será o carvão vegetal e maior será a quantidade de energia liberada por unidade de volume, por consequência menores serão os custos relacionados ao transporte tanto da madeira quanto do carvão. 


\section{Rendimento gravimétrico do carvão vegetal}

As médias para o jatobá neste estudo foram próximas às encontradas na literatura para as marchas de carbonização de $450{ }^{\circ} \mathrm{C}$ e $500{ }^{\circ} \mathrm{C}$ (Tabela 3 ). Trugilho \& Silva (2001) obtiveram médias para o rendimento gravimétrico do carvão de $42,2 \%$ para a temperatura final de $400{ }^{\circ} \mathrm{C}$ e de $35,6 \%$ para temperatura final de carbonização de $500{ }^{\circ} \mathrm{C}$ para Hymenaea courbaril. Os autores observaram que ocorreu um decréscimo mais acentuado do rendimento gravimétrico em temperaturas mais baixas e à medida que se aumentou a temperatura final de carbonização, houve tendência de estabilização do rendimento.

Os valores médios encontrados por Costa et al. (2014) para cinco espécies nativas do cerrado na temperatura final de $450{ }^{\circ} \mathrm{C}$ foram próximos aos das espécies avaliadas neste estudo para a marcha de carbonização de $450{ }^{\circ} \mathrm{C}$. Oliveira et al. (2010), em estudo realizado para avaliar a temperatura final e a velocidade da taxa de aquecimento de Eucalyptus pellita, observaram para temperatura final de carbonização de $450{ }^{\circ} \mathrm{C}$ por $6 \mathrm{~h}$ um rendimento gravimétrico médio de $32,1 \%$ e para temperatura de $500{ }^{\circ} \mathrm{C}$ por $7 \mathrm{~h}$ um rendimento gravimétrico de $31,1 \%$. Os autores observaram que para as temperaturas finais de $450{ }^{\circ} \mathrm{C} \mathrm{e}$ $500{ }^{\circ} \mathrm{C}$ foram encontrados valores altos de rendimento em carvão vegetal e que o rendimento manteve-se estável nessas temperaturas.

Vieira et al. (2013) observaram para a temperatura final de $500{ }^{\circ} \mathrm{C}$ uma média em rendimento gravimétrico do carvão vegetal de $34,0 \%$ para E. microcorys. Os resultados descritos pelos autores foram próximos aos encontrados para os resíduos das espécies em estudo e para as respectivas marchas de carbonização. Segundo Souza et al. (2016), o rendimento médio do carvão oriundo de Eucalyptus sp. é de 50,0\%.

Boas et al. (2010) constataram que com o aumento da temperatura de carbonização, houve decomposição dos constituintes químicos das matérias-primas, provocando perda de massa e, consequentemente, redução no rendimento gravimétrico do carvão. Oliveira et al. (2010) observaram um decréscimo acentuado no rendimento em carvão com o aumento da temperatura final de carbonização. Os autores relataram que este fato pode ter ocorrido devido à degradação térmica incompleta do material. O mesmo foi observado para o presente estudo.

\section{Qualidade do carvão vegetal}

Os resultados obtidos para o jatobá nesse estudo para as marchas de carbonização de temperatura final de 450 e $500^{\circ} \mathrm{C}$ foram próximos aos observados na literatura. A densidade aparente não apresentou influência da marcha de carbonização. Segundo Oliveira et al. (2010), uma explicação para isso poderia ser o fato das marchas de carbonização apresentarem taxas de aquecimento muito próximas. Em estudo realizado por Trugilho \& Silva (2001) sobre a influência da temperatura final da carbonização no carvão de jatobá, foram obtidas médias de $0,53 \mathrm{~g} \mathrm{~cm}^{-3}$ para densidade aparente do carvão na temperatura final de $400{ }^{\circ} \mathrm{C}$ e de $0,52 \mathrm{~g} \mathrm{~cm}^{-3}$ para a temperatura final de carbonização de $500{ }^{\circ} \mathrm{C}$.

$\mathrm{O}$ Eucalyptus é o gênero mais utilizado para produção de carvão vegetal no Brasil. Segundo estudo realizado por Pereira et al. (2016) com o gênero Eucalyptus, as médias de densidade aparente do carvão obtidas foram: $0,36 \mathrm{~g} \mathrm{~cm}^{-3}$ para $E$. camaldulensis, $0,38 \mathrm{~g} \mathrm{~cm}^{-3}$ para $E$. grandis de e $0,40 \mathrm{~g} \mathrm{~cm}^{-3}$ para E. urophylla. Os resultados foram próximos aos obtidos para freijó, angelim-pedra e muiracatiara. Para o ipê o resultado foi superior às médias observadas pelos autores para o gênero Eucalyptus.

A densidade básica da madeira apresentou correlação positiva com a densidade aparente do carvão. Essa resposta era esperada, pois a densidade aparente do carvão está diretamente relacionada à densidade básica da madeira, ou seja, espécies mais densas, apresentarão maior densidade aparente do carvão. Provavelmente isso explica, os valores encontrados para Eucalytus por Pereira et al. (2016) serem próximos aos valores observados para freijó, angelim-pedra e muiracatiara, pois as mesmas apresentaram densidade básica da madeira considerada média, assim como para o Eucalyptus, enquanto que a densidade básica de ipê foi alta (Tabela 2).Vale et al. (2002) observaram comportamento semelhante para espécies nativas do cerrado.

O índice de quebra do carvão apresentou diferenças estatísticas entre as espécies, entre as marchas de carbonização, com interação entre estes dois fatores avaliados ao nível de $1 \%$ de probabilidade. Observou-se na Tabela 4 que as espécies de menor densidade básica da madeira apresentaram menor índice de quebra do carvão. Isto pode ter ocorrido devido às mesmas apresentarem menor massa e pelo fato de não apresentarem defeitos no carvão. A espécie que apresentou a menor média entre as espécies avaliadas foi a muiracatiara $(0,2 \%)$, na marcha de carbonização com temperatura final de $450{ }^{\circ} \mathrm{C}$, 
e a que obteve maior média foi o ipê $(58,7 \%)$, para a marcha de carbonização de $500{ }^{\circ} \mathrm{C}$. As espécies que apresentaram maior índice de quebra do carvão vegetal foram as que apresentaram maior densidade básica da madeira (ipê e jatobá). Isto pode ter ocorrido pelo fato das mesmas serem mais densas e por terem apresentado defeitos como rachaduras. Esse resultado foi observado para as duas marchas de carbonização avaliadas neste estudo.

$\mathrm{Na}$ temperatura final de carbonização de $500{ }^{\circ} \mathrm{C}$ foi possível observar um aumento no índice de quebra do carvão vegetal, quando comparado com a temperatura final de carbonização de $450{ }^{\circ} \mathrm{C}$. Este aumento variou de $0,2 \%$ a $58,7 \%$ e a espécie que apresentou maior percentual de quebra foi o ipê (Tabela 4). Uma possível explicação para este fato é que a mesma apresentou maior densidade básica da madeira e consequentemente maior índice de rachaduras.

O aumento da temperatura na carbonização pode influenciar a resistência mecânica do carvão vegetal. Segundo Costa et al. (2017), a redução na resistência em temperaturas de $450{ }^{\circ} \mathrm{C}$ e $550{ }^{\circ} \mathrm{C}$ pode estar relacionada à saída dos gases voláteis do interior da peça durante a carbonização. Ainda, de acordo com os autores, as contrações que ocorrem no carvão não são significativas, permanecendo o número de fibras por unidade de área constante. Este fato, associado ao aumento da porosidade do carvão, que ocorre devido ao processo de volatilização dos componentes do lenho, pode ser a causa da perda da resistência mecânica do carvão até temperaturas próximas a $500{ }^{\circ} \mathrm{C}$.

Costa et al. (2014), em estudo realizado para cinco espécies nativas do cerrado, encontraram media máxima para o poder calorífico de $7.730 \mathrm{Kcal} \mathrm{kg}^{-1}$ para Trema micrantha e mínima de $7.135 \mathrm{Kcal} \mathrm{kg}^{-1}$ para Luehea divaricata. Os valores foram próximos aos encontrados para as espécies neste estudo (Tabela 5). O valor médio observado nesse trabalho para o jatobá foi superior ao obtido por Trugilho \& Silva (2001) que encontraram valor médio de $6.012,20 \mathrm{Kcal} \mathrm{kg}^{-1}$ para o carvão vegetal de jatobá produzido na marcha de carbonização de $500{ }^{\circ} \mathrm{C}$. Os valores médios encontrados em clone de Eucalyptus pellita por Oliveira et al. (2010) foram de $8.309 \mathrm{Kcal} \mathrm{kg}^{-1}$ para temperatura final de $450{ }^{\circ} \mathrm{C}$ e de $8.237 \mathrm{Kcal} \mathrm{kg}^{-1}$ para a temperatura final de $500{ }^{\circ} \mathrm{C}$.

Pode-se observar que houve um aumento dos valores médios do poder calorífico com o aumento da temperatura final de carbonização do carvão vegetal, o que foi observado para todas as espécies (Tabela 5). Este fato pode ter ocorrido devido ao teor de carbono fixo aumentar com o aumento da temperatura. O teor de carbono fixo, juntamente com o teor de materiais voláteis, são as principais características que determinam o poder calorífico do carvão (Protásio et al., 2011; Reis et al., 2012). Segundo Oliveira et al. (2010), isto ocorre devido às maiores temperaturas implicarem em menores rendimentos e maior teor de carbono fixo e, consequentemente, maior poder calorífico.

\section{Análise química imediata}

Os valores obtidos neste estudo para matérias voláteis do carvão vegetal, foram considerados apropriados por serem baixos, consequentemente apresentando um teor de carbono fixo mais alto (Tabela 6). Constatou-se que com o aumento da temperatura final de carbonização ocorreu uma queda no teor de materiais voláteis. Oliveira et al. (2010), testando diferentes marchas de carbonização, observaram que com o aumento da temperatura final de carbonização, houve diminuição do teor de materiais voláteis. Segundo Brand (2010), baixos teores de materiais voláteis tendem a altos teores de carbono fixo no carvão vegetal, ou seja, eles poderão requerer longo tempo de residência na fornalha para queima total. Em estudo realizado por Brand et al. (2013) para espécie nativa da Mata Atlântica, Miconia cinnamomifolia, o teor de voláteis médio foi de $30,5 \%$ para temperatura final de $450{ }^{\circ} \mathrm{C}$, valores médios foi próximos aos encontrados para as espécies deste estudo (Tabela 6).

Os teores de carbono fixo para as espécies estudadas (Tabela 6) foram próximos aos encontrados por Costa et al. (2014) em estudo do carvão de cinco espécies nativas do cerrado, que relataram valores médios entre $77,2 \%$ e $81,0 \%$.

O percentual de carbono fixo refere-se à fração de carvão que se queima no estado sólido. Combustíveis com teores elevados de carbono fixo são preferíveis para o uso siderúrgico, devido à estabilidade térmica e elevado poder energético (Neves et al., 2011). Os valores de carbono fixo neste estudo encontram-se de acordo a Resolução SAA-40, que altera a Resolução SAA-10, de 11 de julho de 2003 , onde se define a norma de padrões mínimos de qualidade para carvão vegetal, como base para certificação de produtos pelo sistema de qualidade de produtos agrícolas, pecuários e agroindustriais do Estado de São Paulo (São Paulo, 2015). A mesma 
determina valores considerados ideais para um carvão de qualidade: sendo teor de carbono fixo acima de $73 \%$, teor de cinzas abaixo de $1,5 \%$ e o teor de umidade abaixo de 5,0\% (São Paulo, 2015).

Observou-se que para a temperatura final de $500{ }^{\circ} \mathrm{C}$ houve um aumento na concentração de carbono fixo, quando comparado com a temperatura final de $450{ }^{\circ} \mathrm{C}$. Vieira et al. (2013) observaram o mesmo comportamento no carvão produzido a partir de diferentes temperaturas finais de carbonização. Oliveira et al. (2010) observaram que o teor de carbono fixo apresenta correlação negativa com o teor de materiais voláteis, ou seja, durante o processo de carbonização, quanto maior a exposição da madeira a elevadas temperaturas, maior será a intensidade com que as substâncias voláteis se soltam, reduzindo seu teor no carvão.

Os teores de cinzas corresponde a substâncias que não entram em combustão. Os mesmos ficam na forma sólida e são indesejáveis para fins energéticos (Chaves et al., 2013).

Os teores de cinzas para esse estudo foram considerados aceitáveis para freijó, ipê e muiracatiara, pois apresentaram médias inferiores a 1,5\%. Porém, o jatobá apresentou valor acima do aceitável (Tabela 6), de acordo com Resolução SAA-40 (São Paulo, 2015). Protásio et al. (2013) afirmam que são desejáveis menores quantidades de cinzas no carvão vegetal, pois os minerais não sofrem combustão, gerando resíduos e diminuindo o valor calórico do combustível. Trugilho \& Silva (2001) obtiveram um valor médio para o teor de cinzas no carvão vegetal de jatobá de 1,39\%, na temperatura final de $500{ }^{\circ} \mathrm{C}$, sendo o valor inferior ao encontrado nesse estudo para o jatobá.

Observou-se que com o aumento da temperatura final da pirólise, houve um acréscimo do teor de cinzas do carvão (Tabela 6). Uma possível explicação para este fato deve-se ao efeito da concentração de minerais pela perda da massa. Protásio et al. (2011) encontraram teor de cinzas para o carvão vegetal de Qualea parviflora de $2,93 \%$, superior ao relatado neste trabalho. Ainda nesse sentido, Vale et al. (2010) observaram em um estudo realizado para cinco espécies nativas do bioma cerrado, o valor médio de teor cinzas de 7\%, valor também superior ao obtido neste estudo.

O teor de carbono fixo correlacionou-se positivamente com o poder calorífico do carvão vegetal $(\mathrm{r}=0,87916)$. Essa relação corrobora com o observado na literatura (Protásio et al., 2011; Reis et al., 2012; Costa et al., 2014).

\section{Conclusões}

A densidade aparente e o rendimento gravimétrico do carvão vegetal produzido a partir de resíduos das cinco espécies tropicais Cordia geoldiana, Hymenolobium petraeum, Hymenaea courbaril, Tabebuia spp. e Astronium lecointei alcançaram valores médios aceitáveis para a produção de carvão vegetal.

O poder calorífico do carvão aumentou com o aumento da temperatura final para as cinco espécies tropicais, encontrando-se dentro dos padrões de qualidade e apresentando alto potencial energético.

Recomenda-se a utilização do carvão vegetal dos resíduos das espécies estudadas como fonte de energia. A temperatura final de carbonização recomendada foi de $500{ }^{\circ} \mathrm{C}$.

\section{Referências}

American Society for Testing and Materials. ASTM D-176284: standard method for chemical analyses of wood charcoal. Philadelphia, 2007. 2 p.

American Society for Testing and Materials. ASTM D-2395: standard test methods for specific gravity of wood and wood-based materials. Philadelphia, 2005. 8 p.

Associação Brasileira de Normas Técnicas. NBR 7416: carvão vegetal: determinação do índice de quebra. Rio de Janeiro, 1984.

Associação Brasileira de Normas Técnicas. NBR 8112: carvão vegetal: análise imediata. Rio de Janeiro, 1983. 5 p.

Associação Brasileira de Normas Técnicas. NBR 9156: determinação da densidade relativa aparente, relativa verdadeira e porosidade: método de ensaio. Rio de Janeiro, 1985. 8 p.

Boas, M. A. et al. Efeito da temperatura de carbonização e dos resíduos de macaúba na produção de carvão vegetal. Scientia Forestalis, v. 38, n. 87, p. 481-490, 2010.

Brand, M. A. Energia de biomassa florestal. Rio de Janeiro: Interciência, 2010.

Brand, M. A. et al. Análise da qualidade da madeira e do carvão vegetal produzido a partir da espécie Miconia cinnamomifolia (De Candolle) Naudin (Jacatirão-açu) na agricultura familiar, em Biguaçu, Santa Catarina. Scientia Forestalis, v. 41, n. 99, p. 401410, 2013.

Biasi, C. P. \& Rocha, M. P. Rendimento em madeira serrada e quantificação de resíduos para três espécies tropicais. Floresta, v. 37, n. 1, 2007.

Carvalho, A. F. et al. Anatomia do carvão oriundo de cinco espécies comercializadas no estado de Santa Catarina. Revista Ciência da Madeira, v. 8, n. 3, 2017.

Chaves, A. M. B. et al. Características energéticas da madeira e carvão vegetal de clones de Eucalyptus spp. Enciclopédia Biosfera, v. 9, n. 17, p. 533-542, 2013. 
Costa, G. T. et al. Qualidade da madeira de cinco espécies de ocorrência no cerrado para produção de carvão vegetal. Cerne, v. 20, n. 1, 2014. DOI: 10.1590/S0104-77602014000100005.

Costa, L. J. et al. Caracterização mecânica do carvão vegetal de clones Corymbia. Scientia Forestalis, v. 45, n. 116, p. 629-639, 2017. DOI: 10.18671/scifor.v45n116.04.

FAO. Wood energy. 2017. Avaliable from: <http://www.fao.org/ forestry/energy/en/>. Access on: 21 maio 2018.

Froehlich, P. L. \& Moura, A. Carvão vegetal: propriedades físicoquímicas e principais aplicações. Tecnologia e Tendências, v. 9, n. 1, p. 13-32, 2017.

Leite, E. R. et al. Qualidade do carvão vegetal produzido a partir da madeira do cafeeiro, para uso bioenergético. Coffee Science, v. 10, n. 2, p. 251-261, 2015. DOI: 10.25186/cs.v10i2.881.

Lima, N. et al. Propriedades físico-mecânicas de painéis LVL produzidos com três espécies amazônicas. Cerne, v. 19, n. 3, 2013. DOI: $10.1590 / \mathrm{S} 0104-77602013000300007$.

Neves, T. A. et al. Avaliação de clones de Eucalyptus em diferentes locais visando à produção de carvão vegetal. Pesquisa Florestal Brasileira, v. 31, n. 68, p. 319, 2011. DOI: 10.4336/2011. pfb.31.68.319.

Oliveira, A. C. et al. Parâmetros da qualidade da madeira e do carvão vegetal de Eucalyptus pellita F. Muell. Scientia Forestalis, v. 38, n. 87, p. 431-439, 2010.

Pereira, C. B. L. et al. Efeito da carbonização da madeira na estrutura anatômica e densidade do carvão vegetal de Eucalyptus. Ciência Florestal, v. 26, n. 2, 2016. DOI: 10.5902/1980509822755.

Protásio, T. P. et al. Avaliação da qualidade do carvão vegetal de Qualea parviflora. Pesquisa Florestal Brasileira, v. 31, n. 68, p. 295-307, 2011. DOI: 10.4336/2011.pfb.31.68.295.

Protásio, T. P. et al. Potencial siderúrgico e energético do carvão vegetal de clones de Eucalyptus spp. aos 42 meses de idade. Pesquisa Florestal Brasileira, v. 33, n. 74, p. 137-149, 2013. DOI: 10.4336/2013.pfb.33.74.448.
Reis, A. A. et al. Composição da madeira e do carvão vegetal de Eucalyptus urophylla em diferentes locais de plantio. Pesquisa Florestal Brasileira, v. 32, n. 71, p. 277-290, 2012.

Rodrigues, P. L. et al. Participação popular na implantação da primeira concessão de floresta pública brasileira-Floresta Nacional do Jamari-RO (Flona Jamari). 2011. 117 f. Dissertação (Mestrado em Gestão Ambiental) - Universidade Católica de Brasília, Brasília, DF.

Santos, R. C. et al. Correlações entre os parâmetros de qualidade da madeira e do carvão vegetal de clones de eucalipto. Scientia Forestalis, v. 39, n. 90, p. 221-230, 2011.

São Paulo (Estado). Resolução SAA-40 de 14 de dezembro de 2015. Norma de padrões mínimos de qualidade para carvão vegetal. São Paulo, 2015.

Souza, N. D. et al. Estudo de caso de uma planta de carbonização: avaliação de características e qualidade do carvão vegetal visando uso siderúrgico. Floresta e Ambiente, v. 23, n. 2, p. 270-277, 2016.

Trugilho, P. F. \& Silva, D. A. D. Influência da temperatura final de carbonização nas características físicas e químicas do carvão vegetal de jatobá (Himenea courbaril L.). Scientia Agraria, v. 2, n. 1-2, 2001. DOI: 10.5380/rsa.v2i1.976.

Vale, A. T. et al. Estimativa do poder calorífico superior do carvão vegetal de madeiras de Eucalyptus grandis em função do teor de carbono fixo e do teor de material volátil. Revista Brasil Florestal, n. 73,2002 .

Vale, A. T. et al. Relação entre as propriedades químicas, físicas e energéticas da madeira de cinco espécies do cerrado. Ciência Florestal, v. 20, n. 1, p. 137-145, 2010.

Vieira, R. S. et al. Influência da temperatura no rendimento dos produtos da carbonização de Eucalyptus microcorys. Revista Cerne, v. 19, n. 1, p. 59-64, 2013. DOI: 10.1590/S0104-77602013000100008. 